\title{
Imaging-Guided Superior Ophthalmic Vein Access for Embolization of Dural Carotid Cavernous Fistulas: Report of 20 Cases and Review of the Literature
}

\author{
(D) M.K.S. Heran, (DD. Volders, (D) C. Haw, and DJ.R. Shewchuk
}

\begin{abstract}
SUMMARY: Dural carotid cavernous fistulas are usually treated via a transvenous approach through the inferior petrosal sinus. Surgical exposure and direct access to the superior ophthalmic vein have been previously described in situations in which conventional transvenous access, including the inferior petrosal sinus, is not possible. In this retrospective study of 20 patients, we report our results of imaging-guided percutaneous superior ophthalmic vein access in dural carotid cavernous fistula treatment. The superior ophthalmic vein was accessed after direct percutaneous puncture under sonographic guidance in 16 patients and biplane roadmap guidance in 4 patients. In all 20 patients, it was possible to access the superior ophthalmic vein and cure the dural carotid cavernous fistula. Two patients developed a retrobulbar hematoma after postseptal puncture, which required emergency lateral canthothomy. In our experience, direct imaging-guided percutaneous superior ophthalmic vein access is a safe alternative approach for treatment in situations in which conventional transvenous approaches are not possible.
\end{abstract}

ABBREVIATIONS: dCCF = dural carotid cavernous fistula; IPS = inferior petrosal sinus; SOV = superior ophthalmic vein

D

ural arteriovenous fistulas represent $10 \%-15 \%$ of intracranial high-flow lesions. ${ }^{1-3}$ Dural arteriovenous fistulas consist of a nidus of multiple fistulas in the wall of the dural sinus. The arterial feeders are mostly meningeal branches arising from the external carotid artery or internal carotid artery. Dural arteriovenous fistulas are usually acquired conditions occurring in postmenopausal women. ${ }^{1,4,5}$ Occasionally, they occur in younger patients in association with pregnancy or are related to prior trauma or surgery. ${ }^{6}$ A dural carotid cavernous fistula (dCCF) is a specific type of dural arteriovenous fistula characterized by abnormal arteriovenous shunting within the cavernous sinus. Barrow et $\mathrm{al}^{5}$ classified dCCFs into 4 groups according to arterial feeders. Types $\mathrm{B}, \mathrm{C}$, and $\mathrm{D}$ are dural fistulas, with supply respectively arising from the ICA only, the external carotid artery only, or both the ICA and external carotid artery. The arterialized blood usually drains into the dural sinus itself, either directly or indirectly

Received October 26, 2018; accepted after revision January 23, 2019.

From the Department of Radiology (M.K.S.H., D.V., J.R.S.), University of British Columbia, Vancouver, British Columbia, Canada; Division of Neuroradiology (M.K.S.H., J.R.S.) and Department of Neurosurgery (C.H.), Vancouver General Hospital, University of British Columbia, Vancouver, British Columbia, Canada; and Department of Radiology (M.K.S.H.), British Columbia's Children's Hospital, University of British

Columbia, Vancouver, British Columbia, Canada.

Manraj K.S. Heran and David Volders contributed equally to this work.

Please address correspondence to Manraj K.S. Heran, MD, FRCPC, Division of Neuroradiology, Vancouver General Hospital, University of British Columbia, 899 West 12th Ave, Vancouver, BC Canada V5Z 1M9; e-mail: manraj.heran@vch.ca

http://dx.doi.org/10.3174/ajnr.A5994 through venous anastomoses. Symptoms are typically related to the route of venous drainage and the degree of shunting. ${ }^{7-9}$ When venous drainage is diverted to the ophthalmic veins, ocular symptoms such as conjunctival injection, diplopia, glaucoma, and proptosis may occur. ${ }^{1,4}$ The natural evolution of dCCF is variable, and some may spontaneously resolve by thrombosis of the fistula. ${ }^{1,7}$

Treatment is considered in those cases in which symptoms persist or worsen. dCCF can be treated by transvenous and/or transarterial endovascular techniques. The transvenous route is usually preferred and is performed by accessing the cavernous sinus via the inferior petrosal sinus (IPS) through the internal jugular vein, with embolization of the cavernous sinus then performed. In the case of a thrombosed IPS, access through the obstructed sinus is not always possible and access to the cavernous sinus can be achieved through other venous approaches such as the contralateral IPS and across intercavernous sinus communications or via the superior ophthalmic vein (SOV). Previous case studies have described an operative exposure of the SOV, with placement of a vascular sheath into the SOV under direct visualization. ${ }^{10,11}$ Given the limited number of case studies describing imaging-guided access rather than operative exposure, we present our experience in obtaining minimally invasive imaging-guided access to the SOV in situations in which conventional transvenous access to the cavernous sinus is not possible for management of patients with dCCF.

AJNR Am J Neuroradiol 40:699-702 Apr 2019 www.ajnr.org 


\begin{tabular}{|c|c|c|c|c|c|}
\hline $\begin{array}{c}\text { Age } \\
(y r) / \text { Sex }\end{array}$ & Side & $\begin{array}{c}\text { IPS } \\
\text { Outflow }\end{array}$ & Imaging & Puncture & Hematoma \\
\hline $67 / F$ & Left & None & US & Preseptal & None \\
\hline $66 / M$ & Right & None & US & Preseptal & None \\
\hline $59 / \mathrm{M}$ & Left & None & $\begin{array}{l}\text { Biplane } \\
\text { roadmap }\end{array}$ & Postseptal & Preseptal \\
\hline $18 / F$ & Right & None & US & Preseptal & Preseptal \\
\hline $59 / F$ & Left & None & US & Postseptal & None \\
\hline $47 / F$ & Bilateral & None & US & Preseptal & Preseptal \\
\hline $98 / F$ & Right & None & US & Preseptal & None \\
\hline $77 / F$ & Left & None & US & Preseptal & None \\
\hline $71 / F$ & Left & None & US & Preseptal & None \\
\hline $70 / M$ & Right & None & US & Preseptal & None \\
\hline $84 / F$ & Left & Minimal & US & Preseptal & None \\
\hline $69 / \mathrm{F}$ & Right & None & $\begin{array}{l}\text { Biplane } \\
\text { roadmap }\end{array}$ & Preseptal & Preseptal \\
\hline $66 / M$ & Right & None & US & Postseptal & Retrobulbar \\
\hline $66 / F$ & Bilateral & Minimal & US & Preseptal & None \\
\hline $75 / \mathrm{M}$ & Right & None & US & Preseptal & None \\
\hline $27 / F$ & Right & None & $\begin{array}{l}\text { Biplane } \\
\text { roadmap }\end{array}$ & Postseptal & Retrobulbar \\
\hline $67 / F$ & Bilateral & Minimal & $\begin{array}{l}\text { Biplane } \\
\text { roadmap }\end{array}$ & Preseptal & None \\
\hline $76 / F$ & Right & None & US & Preseptal & None \\
\hline $56 / F$ & Right & None & US & Preseptal & None \\
\hline $73 / F$ & Left & None & US & Preseptal & None \\
\hline
\end{tabular}

Note:-US indicates ultrasound

${ }^{\text {a }}$ All patients achieved an angiographic cure.

\section{Case Series}

Between July 2012 and November 2017, twenty patients underwent endovascular treatment for dCCF with transvenous embolization after percutaneous imaging-guided SOV puncture (Table). All procedures were performed with the patient under general anesthesia without administration of heparin. The patient group consisted of 5 male and 15 female patients (age range, 18-98 years; mean, 67 years). In all patients, the SOV was evaluated with a high-frequency 15- to 7-MHz hockey stick sonography probe (Philips, Markham, Ontario, Canada) using a broadband acoustic lens for imaging at the transducer surface. Endovascular procedures were performed with an Allura Xper FD 20/20 biplane system (Philips Healthcare, Best, the Netherlands) with high-quality roadmap technology. The SOV could be accessed by sonography in 16 patients (Fig 1). In the remaining 4 patients, SOV access was obtained using biplane roadmap (Philips Healthcare) with a biplane road-mapping technique (Fig 2). The SOV was accessed preseptally in 16 patients. In 4 patients, the SOV had to be accessed in a postseptal location due to SOV thrombosis (2 patients) or high-grade stenosis at the ophthalmic-trochlear vein junction (2 patients). The vascular approach was through the trochlear vein in 2 cases and the SOV in 18 cases. Clinical findings included proptosis and chemosis (20 patients), diplopia and increased ocular pressure (13 patients), decreased visual acuity (13 patients), and sixth nerve palsy ( 1 patient). The dCCF was on the right side in 10, on the left side in 7 , and bilateral in 3 cases. Nineteen dCCF cases were spontaneous, and 1 case was post-traumatic. In most lesions (18/20), the arterial supply was from both the internal and external carotid arteries (type D, Barrow classification). Two cases were of Barrow types B and C, in which arterial supply was from the internal or external carotid artery, respectively.

Treatment indications with an SOV approach included IPS thrombosis and/or cavernous sinus compartmentalization pre- cluding access to the anterior part of the cavernous sinus from the IPS, favorable anatomic configuration with predominant venous drainage toward the SOV, and type D dCCF.

In 17 of 20 patients, dCCF venous drainage did not flow toward the IPS due to IPS occlusion/thrombosis. In 3 patients, the IPS was visualized during the late venous phase of carotid angiography, indicating patency without communication between the IPS and cavernous sinus compartment with its dCCF shunts. All 20 patients were treated during 1 embolization session, with elimination of the fistula in all cases.

Our standard vascular imaging-guided orbital approach was a preseptal SOV puncture with a 22-ga angiocatheter cannula with initial placement of a 0.014 -inch Transend guidewire (Stryker, Kalamazoo, Michigan) in the cavernous sinus. Subsequently, the $2 \mathrm{~F}$ inner cannula of a micropuncture access set (Cook, Bloomington, Indiana) was advanced over the guidewire and the Transend guidewire was exchanged for a stiffer V-18 guidewire (Boston Scientific, Natick, Massachusetts) to upsize the entire access to the $4 \mathrm{~F}$ or $5 \mathrm{~F}$ outer micropuncture cannula in the SOV. This cannula was connected to a system of two 30-cm connection tubes (Cook) and a Tuohy Borst hemostatic valve (Merit Medical, South Jordan, Utah). In 2 cases, we used a Synchro 0.014-inch (Stryker) guidewire instead of the Transend guidewire. In 3 cases, we used a 24-ga angiocatheter cannula instead of the 22-ga angiocatheter cannula due to the smaller SOV size. Hydrophilic microcatheters used were PX SLIM (Penumbra, Alameda, California) in 8 cases, Excelsior SL-10 (Stryker) in 6 cases, and Renegade (Boston Scientific) in 4 cases (in the earlier cases in the series).

Coiling was performed starting from the posterior part of the cavernous sinus moving anteriorly to the level of the SOV using PC400 and Smart coils (Penumbra, Alameda, California) and Target detachable coils (Stryker Neurovascular). We finished the embolization by Gelfoam (Pfizer, New York, New York) of the SOV through the $4 \mathrm{~F}$ or $5 \mathrm{~F}$ micropuncture cannula before sheath removal. Control angiography was performed during the procedure from a $4 \mathrm{~F}$ or $5 \mathrm{~F}$ catheter, which was selectively positioned into the feeding arteries. Clinical charts and radiologic studies were retrospectively reviewed after ethics committee approval.

In all 20 cases, it was possible to catheterize the SOV under imaging guidance, to reach the cavernous sinus, and to treat the dCCF with an angiographic cure. In most cases (14/20), the procedure was uneventful. In 4 cases, a procedural preseptal hematoma developed, which did not require further management. In 2 cases of postseptal SOV puncture, 1 sonography and 1 biplane roadmap, increased chemosis and proptosis of the ipsilateral globe was seen due to a developing retrobulbar hematoma, with increased intraocular pressure of $>50 \mathrm{~mm} \mathrm{Hg}$ (normal pressure is $12-22 \mathrm{~mm} \mathrm{Hg}$ ). After we successfully embolized the dCCF, our colleagues from ophthalmology performed a lateral canthothomy in the angiography suite. The intraocular pressure immediately normalized in both cases after decompressive canthothomy $(<20$ $\mathrm{mm} \mathrm{Hg}$ ). Angiographic cure was seen in all 20 patients. Clinical cure was achieved in 15 patients, and improvement was achieved in 5 . The 2 patients who developed a postseptal hematoma had normalization of their vision with no residual visual symptoms from their dCCF. 


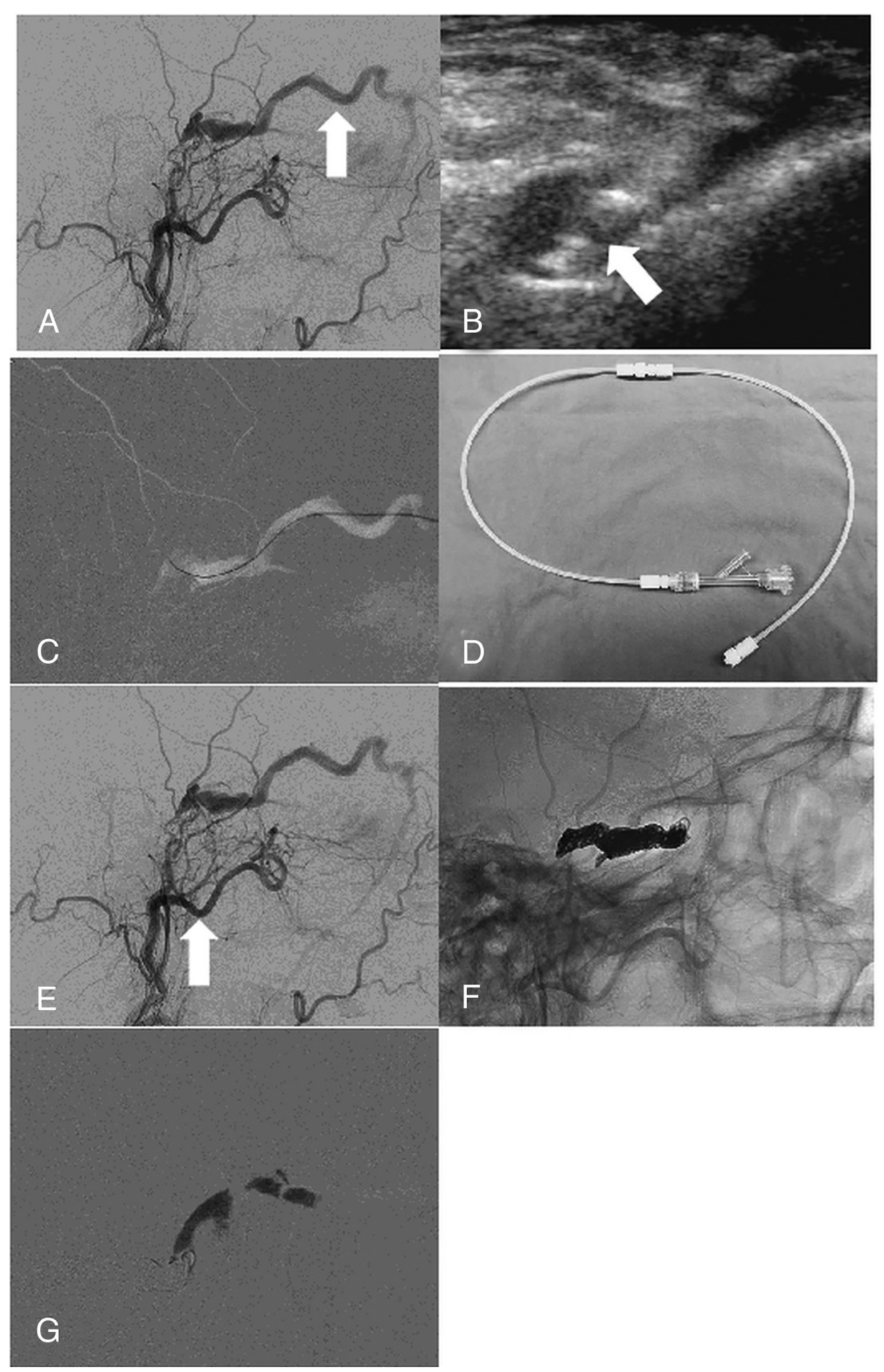

FIG 1. dCCF of the right cavernous sinus in a 56-year-old woman. A, Lateral-view angiogram from the right external carotid artery, obtained before embolization, shows a dCCF. The inferior petrosal sinus is thrombosed at the level of its inferior portion. There is predominant venous drainage toward the SOV (arrow). B, Direct percutaneous sonographically guided SOV puncture with a 22- or 24-ga angiocatheter cannula (arrow) using a high-frequency 15- to 7-MHz hockey stick sonography probe. C, Lateral-view roadmap, obtained after injecting the right external carotid artery, shows how a Transend 0.014 -inch guidewire is advanced to the posterior aspect of the cavernous sinus. This allows subsequent exchange of a $2 \mathrm{~F}$ inner for a $4 \mathrm{~F}$ outer piece of a micropuncture set over a V-18 guidewire. $D$, Connecting system of two $30-\mathrm{cm}$ connecting tubes and a Tuohy Borst hemostatic valve, which is connected to the micropuncture cannula. E, Lateralview angiogram from the right external carotid artery shows the location in the posterior part of the cavernous sinus where a PX Slim microcatheter is placed (arrow). F, Lateral subtracted-view angiogram from the right external carotid artery shows how the coils are placed from posterior to anterior. G, Lateral blank subtraction roadmap demonstrating Gelfoam embolization of SOV from downstream to upstream while withdrawing the micropuncture cannula.

\section{DISCUSSION}

dCCFs are, in most cases, treated by endovascular cavernous sinus embolization using a transvenous approach, typically via the IPS.
However, in some patients, this access is absent due to IPS thrombosis or anatomic variation with an absent connection between the IPS and internal jugular vein. In these scenarios, endovascular access to the cavernous sinus through direct surgical access of the dilated SOV can be a useful alternative route, a technique that has been described by several authors in the literature previously. ${ }^{10,11}$

There are, however, only a few reports that specifically focus on imagingguided percutaneous SOV access for treatment of a dCCF. In our large case series, we were able to demonstrate that imaging-guided SOV access can be a very valuable alternative to surgical SOV access, with angiographic cure in all of our patients (20/20) and an acceptable risk of associated complications.

The 2 imaging modalities to access the SOV are sonography and fluoroscopic roadmap-assisted techniques, such as biplane roadmap. Of these 2 techniques, real-time sonography-guided access is our preferred first-line approach. We start our procedure by evaluating the size of the SOV, as well as potential problems we may encounter during direct puncture, such as vascular stenosis and loops, as well as the ability to access the SOV in a preseptal location.

The major advantage of imagingguided SOV access over surgical SOV exposure is that imaging-guided access is less traumatic and avoids (sometimes difficult) coordination of services. The patient does not need to transfer from the operating theater to the angiography suite (if the surgeon chooses to perform the cutdown and exposure in the surgical suite), and the procedure can be performed in a 1-step process. There are also disadvantages to surgical exposure of the SOV because this, too, has an associated learning curve. Specific disadvantages include cut-down and cutaneous scars, which can be cosmetically important. ${ }^{12,13}$ Oishi et $\mathrm{al}^{14}$ reported blepharoptosis and bilateral forehead dysesthesia in patients undergoing surgical SOV exposure.

Choosing a pre- or postseptal access to the SOV can have important implications. None of the patients $(0 / 16)$ with a preseptal SOV access had a major complication. In 4 patients (4/16), a preseptal hematoma developed during the procedure. However, these resolved without issue in all 

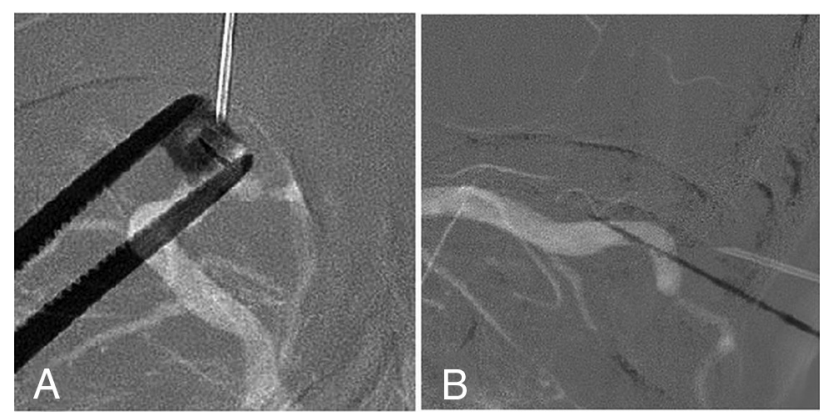

FIG 2. dCCF of the right cavernous sinus in a 66-year-old man. Anteroposterior $(A)$ and lateral $(B)$ view roadmap, obtained after injecting the right external carotid artery, shows how the needle is directed toward the SOV.

cases. This minor complication does not require active management, and it will settle spontaneously within a week.

In situations in which preseptal SOV access is not possible, postseptal SOV puncture can be performed. In our case series, we had 4 patients in whom we performed a postseptal SOV puncture (4/20). Despite our being able to access the SOV in all 4 cases, 2 patients (2/4) developed a retrobulbar hematoma shortly after SOV access. Contrary to a preseptal hematoma, which is a relatively benign condition, a postseptal hematoma is a potentially dangerous condition that can result in increased intraorbital pressure with permanent vision compromise. In the situation of worrisome increased intraorbital pressure, emergency lateral canthothomy is a low-morbidity procedure to relieve the intraorbital pressure, which can easily be performed in the angiography suite. The 2 patients in our case series who developed a retrobulbar hematoma requiring lateral canthothomy had immediate relief of their elevated intraocular pressure and rapid normalization of their vision after the procedure.

In our experience, an initial attempt at SOV access should always be performed preseptally because of the low associated morbidity. Only if this approach is unsuccessful or not possible may postseptal puncture be considered in experienced hands. In this scenario, it is crucial to observe clinical signs of increased intraocular pressure such as proptosis and to have close communication with the ophthalmology service in case lateral canthothomy may be required.

Potential limitations of this study are its retrospective nature and not being a randomized controlled trial in which we compare our technique with surgical SOV exposure. Complications of SOV exposure include bleeding and difficulty in identifying the vein. Some authors have also reported injury of the levator muscle and supraorbital nerve, infection, granuloma, and damage to the trochlea. ${ }^{15}$

\section{CONCLUSIONS}

Minimally invasive percutaneous imaging-guided access to the SOV can be obtained in situations in which conventional trans- venous access to the cavernous sinus is not possible for management of patients with dCCF. In our experience, direct imagingguided percutaneous SOV access is a valuable and time-saving alternative route compared with direct surgical SOV access.

Disclosures: Jason R. Shewchuk—UNRELATED: Travel/Accommodations/Meeting Expenses Unrelated to Activities Listed: European Society of Neuroradiology, Comments: Travel and accommodations reimbursed as invited speaker to European Course in Neuroradiology in May 2018.

\section{REFERENCES}

1. Newton T, Hoyt W. Dural arteriovenous shunts in the region of the cavernous sinus. Neuroradiology 1970;1:71-81 CrossRef

2. Halbach V, Hieshima G, Higashida R, et al. Carotid cavernous fistulae: indications for urgent treatment. AJR Am J Roentgenol 1987;8:627-33 Medline

3. Toya S, Shiobara R, Izumi J, et al. Spontaneous carotid-cavernous fistula during pregnancy or in the postpartum stage: report of two cases. J Neurosurg 1981;54:252-56 Medline

4. Phelps $\mathrm{C}$, Thompson $\mathrm{H}$, Ossoinig $\mathrm{K}$. The diagnosis and prognosis of atypical carotid-cavernous fistula (red-eye shunt syndrome). $\mathrm{Am} J$ Ophthalmol 1982;93:423-36 CrossRef Medline

5. Barrow D, Spector R, Braun I, et al. Classification and treatment of spontaneous carotid cavernous fistulas. J Neurosurg 1985;62:248-56 Medline

6. Watanabe A, Takahara Y, Ibuchi Y, et al. Two cases of dural arteriovenous malformation occurring after intracranial surgery. Neuroradiology 1984;26:375-80 CrossRef Medline

7. Viñuela F, Fox A, Debrun G, et al. Spontaneous carotid-cavernous fistulas: clinical, radiological and therapeutic considerationsexperience with 20 cases. J Neurosurg 1984;60:976-84 Medline

8. Lasjaunias P, Chiu M, ter Brugge K, et al. Neurological manifestations in intracranial dural arteriovenous malformations. J Neurosurg 1986;64:724-30 Medline

9. Awad I, Little J, Akrawi W, et al. Intracranial dural arteriovenous malformations: factors predisposing to an aggressive neurological course. J Neurosurg 1990;72:839-50 Medline

10. Miller NR, Monsein LH, Debrun GM, et al. Treatment of carotidcavernous sinus fistulas using a superior ophthalmic vein approach. J Neurosurg 1995;83:838-42 Medline

11. Biondi A, Milea D, Cognard C, et al. Cavernous sinus dural fistulae treated by transvenous approach through the facial vein: report of seven cases and review of the literature. AJNR Am J Neuroradiol 2003;24:1240-46 Medline

12. Goldberg RA, Goldey SH, Duckwiler G, et al. Management of cavernous sinus-dural fistulas: indications and techniques for primary embolization via the superior ophthalmic vein. Arch Ophthalmol 1996;114:707-14 Medline

13. Naito I, Magarisawa $S$, Wada H. Facial vein approach by direct puncture at the base of the mandible for dural carotid-cavernous fistula: an alternative to the superior ophthalmic vein approach-a case report. Interv Neuroradiol 2002;8:67-70 CrossRef Medline

14. Oishi H, Arai H, Sato K, et al. Complications associated with transvenous embolisation of cavernous dural arteriovenous fistula. Acta Neurochir (Wien) 1999;141:1265-71 CrossRef Medline

15. Quiñones D, Duckwiler G, Gobin PY, et al. Embolization of dural cavernous fistulas via superior ophthalmic vein approach. AJNR Am J Neuroradiol 1997;18:921-28 Medline 